\title{
Design of Humanized Public Bicycle Station Based on Solar Energy Huaixiang Li
}

North China Electric Power University, Beijing, 102206

alanncepu@foxmail.com

\begin{abstract}
Keywords: Solar energy; Public bicycle station; Distributed photovoltaic; Energy conservation and emission reduction
\end{abstract}

\begin{abstract}
In order to solve the management problem of public bicycle, the life problem of electric bicycle and the difficult of urban photovoltaic power generation, we put forward the design scheme of humanized public bicycle station based on solar energy. This product uses solar panels to generate electricity, battery to storage energy. The stored energy converts to alternating current by the inverter system. Power can be supplied to electric bicycles, advertising screens and other equipment. The significance of this product is: (1) Meet the electric bicycles charging needs and the public bicycles and electric bicycles parking needs; (2) Facilitate the management and scheduling of public bicycles and extend the lives of public bicycles; (3) Use distributed photovoltaic efficiently, achieve regional energy self-sufficiency and expand social service; (4) Advertising revenue and charging revenue can balance the operation of the station. To sum up, the station is humanized and of energy conservation and emission reduction. It has a good practical operation and can be popular to market and serve the people.
\end{abstract}

\section{Design Background}

At present, the traditional energy pollution problems are increasing, the development and utilization of clean energy is a major concern in today's world. As a distributed energy, solar energy has unstable energy production and high cost of transmission and transportation.

With the "Internet + " shared economic model gradually rising, a large number of public bicycles such as OFO come to our daily lives. They alleviate traffic pressure and reduce carbon emission, while faced with problems such as excessive depreciation rate and poor management.

As an important means of transport, Electric bicycle is light and fast, economic and environmental. Meanwhile, its mileage is short, storage and other small objective factors, restricting the scope of the activities of electric bicycles, limiting its development potential.

In view of public bicycle management issues, electric bicycle life problems and the use of urban photovoltaic power generation difficult situation on the above, we put forward the design of humanized public bicycle station based on solar energy.

\section{Design Scheme}

Appearance Design. According to the "local conditions" principle, we designed a public bicycle station based on the transformation of bus station. The appearance is showing in figure 1 . The station uses the solar panels 1 as the ceiling of the station, supported by the bracket system 2 . According to the practical application of the principle and the golden split ratio, the station area is divided into parking charging area 3 and waiting area 4, making the width ratio of 3 and 4 be 0.618 and the station beautiful. The parking charging area 3 is provided with a circuit arrangement 5 which comprises a circuit part of the system and a charging device. There are two advertising screen 6 and two bus stop 7 between 3 and 4. The waiting area 4 is equipped with a vending machine 8 and two leisure benches 9 .

In order to obtain more solar energy, according to statistics, in solar photovoltaic power generation applications, we usually place the solar panels towards the equator fixed, and with the horizontal plane to form a certain tilt angle. In the solar engineering design, the choice of the best dip is an important technical problem in different regions. Take Beijing area as an example, to 
maximize the annual production capacity of solar panels, we chose $37^{\circ}$ as the tilt angle. At this time, the annual generating capacity is $191.7 \mathrm{kWh}$ per square meter and the average annual power generation efficiency is $11.77 \%$.

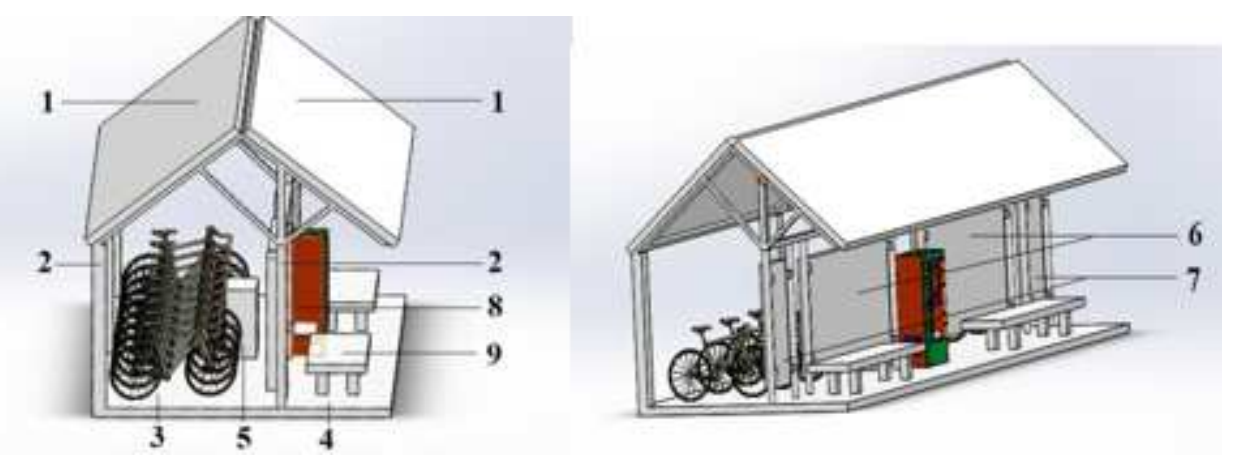

Figure 1. The appearance of reconstructed bus station

The specific transformation programs are as follows:

(1) To achieve the transformation of solar energy utilization, we put solar panels as bus station ceiling.

(2) The rear side of the stop is for charging and storage, making full use of energy.

(3) On the stop sign, besides road map, there are electronic advertising screen and paper billboards.

(4) Establish wireless LAN site, make Residents' life more convenient, attract the crowd to gather and maximize advertising revenue.

Circuit Design. The circuit can be divided into power acquisition system and power system. In the power acquisition system, solar panels collect and convert solar energy. The battery pack stores energy. The solar energy stored in the energy collection system can be converted into electricity, which supply to vending machine, public electric bicycle, advertising screen, mobile equipment and station lights. These will contribute to regional energy self-sufficiency and social service development.

As is shown in fig. 2, the solar panels, battery packs, and loads are connected to the controller. The controller can automatically complete the collection and storage of solar energy links. Through manual control, output power and output voltage can be controlled. To meet the needs of different loads, we add the inverter to the circuit. Then, the DC can be converted into alternating current.

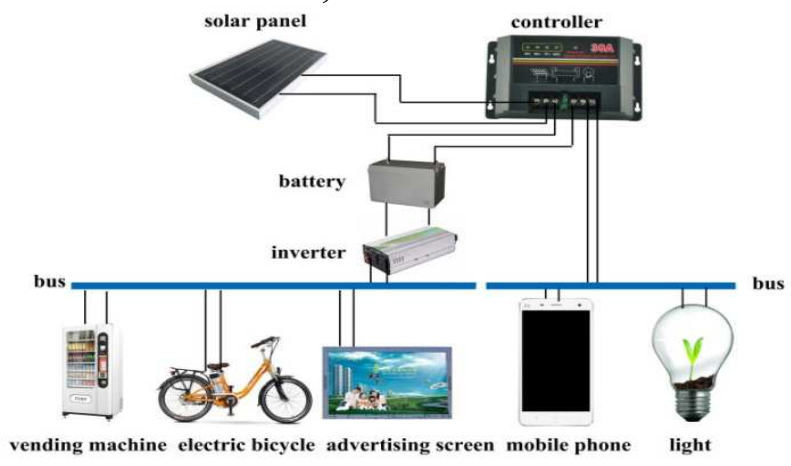

Figure 2. Circuit design

\section{Calculation of Energy Saving and Emission Reduction of Stations}

Calculation of Energy Budget of PV System. Lculation of Power Generation. A single solar panel is the energy supply unit for the Inn. We select technical parameters of representative solar panels. Assuming the effective solar panels installation area of this station is 120 square meters, the capacity of a single battery pack is $200 \mathrm{~W}$, and the capacity of each solar module is $18.9 \mathrm{~kW}$. The factors that affect the power generation capacity of PV power are solar radiation, the tilt angle of 
battery components, the efficiency of battery components, the combination loss, temperature characteristics, dust and rain loss, the maximum of output power tracking (MPPT), line loss, controller power loss, inverter power loss and so on.

In this study, the tilt angle of the solar panel is $37^{\circ}$, the efficiency of the solar panel is $15.6 \%$, the combination loss is $3.2 \%$, the temperature characteristic is $3.1 \%$, the dust and rainwater loss is $7.7 \%$, the line loss is $4.2 \%$, the controller efficiency is $4.3 \%$, the inverter efficiency is $4.3 \%$. Then we get the efficiency of the system is $75.96 \%$. The calculation of power generation is shown in table 1.

Table 1 Alculation of power generation

\begin{tabular}{|c|c|c|c|c|c|}
\hline Month & $\begin{array}{c}\text { Radiation } \\
\text { quantity } \\
/ \mathrm{kWh} \cdot\left(\mathrm{m}^{2} \cdot \mathrm{d}\right) \wedge(- \\
1)\end{array}$ & $\begin{array}{c}\text { Average daily } \\
\text { power generation } \\
/ \mathrm{kWh}\end{array}$ & Month & $\begin{array}{c}\text { Radiation } \\
\text { quantity } \\
/ \mathrm{kWh}\left(\mathrm{m}^{2} \cdot \mathrm{d}\right)^{\wedge}(- \\
1)\end{array}$ & $\begin{array}{c}\text { Average daily } \\
\text { power generation } \\
/ \mathrm{kWh}\end{array}$ \\
\hline January & 1.81 & 43.66 & July & 3.18 & 76.66 \\
\hline February & 2.12 & 51.09 & August & 3.74 & 90.16 \\
\hline March & 2.53 & 60.98 & September & 2.40 & 57.82 \\
\hline April & 3.37 & 81.13 & October & 2.54 & 61.11 \\
\hline May & 3.09 & 74.62 & November & 1.70 & 40.90 \\
\hline June & 3.44 & 82.77 & December & 1.88 & 34.57 \\
\hline
\end{tabular}

Through the power detection of the actual model, we find that the actual power and the theoretical calculation are basically consistent. Therefore, the theoretical calculation is sufficiently reliable.

Power Usage Analysis. Electrical equipment mainly includes public bicycles, advertising screens, lights and mobile equipment. The main function of the station is to provide place for electric bicycle charging. Based on the reference data and the actual measurement, we get the electricity consumption of some power equipment of the station .Show in table 2.

Table 2 Ome power equipment of the station

\begin{tabular}{|c|c|c|c|}
\hline Species & Power/w & Operating hours/h & Quantity /piece \\
\hline Vending machine & 450 & 24 & 1 \\
\hline Mobile equipment & 5 & 12 & 10 \\
\hline Lighting equipment & 12 & 12 & 5 \\
\hline Advertising screen & 165 & 24 & 2 \\
\hline
\end{tabular}

The total energy consumption can be defined as $w_{c}$.It is:

$$
W_{C}=\sum_{i=1}^{4} W_{i}=20.04 \mathrm{kWh}
$$

From Table 1, we get average daily power generation $\left(W_{s}\right)$ is $63.02 \mathrm{kWh}$. Besides the station equipment usage, the remaining energy is used for electric bicycle charging. Through the market survey, an electric bicycle needs $0.48 \mathrm{kWh}$ from no power to full power. We defined it as $W_{i}$. We get the station can charge for $\mathrm{N}$ electric bicycles in the normal working conditions.

$$
N=\frac{W_{S}-W_{C}}{W_{i}}=\frac{63.02-20.04}{0.48} \approx 90
$$

To sum up, 100 stations can generate $6302 \mathrm{kWh}$ each day. It can reduce the capacity of thermal power and achieve the goal of energy transformation. At the same time, 100 stations can supply 
9,000 bicycles with power apart from station equipment power consumption. It contributes to achieving regional power self-sufficiency.

Reduction of Emissions. know $W_{z}$ is $63.02 \mathrm{kWh}$. In a thermal power plant, the coal consumption of a thermal power plant is $292 \mathrm{~g} / \mathrm{kWh}$. Received base carbon $C_{a r}$ is $64.4 \%$. Received sulfur $S_{a r}$ is $0.43 \%$.

We can get:

The amount of fuel required $18.4 \mathrm{~kg}$;

Carbon dioxide emissions: $22.115 \mathrm{~m}^{3}$

Sulfur dioxide emissions: $0.056 \mathrm{~m}^{3}$

After calculation, we can see that 100 stations can reduce 807,197 cubic meters carbon dioxide (It is equivalent to the carbon dioxide emission of 2826 cars in a year.) and 2044 cubic meters sulfur dioxide in a year.

Analysis of Life Extension. For electric bicycle, its service life mainly depends on the using time of power storage equipment. Long time exposed to the sun light leads to life reduction of the battery. At the same time, the main body of the frame is influenced by the rain and other attachments. It is easy to be damaged. If bicycles are parked in the station, the damage rate of them will be reduced and their lives will be longer.

Project Costs and Profits. Solar panels, advertising screens, bus stop signs, vending machines, benches, circuit devices, steel frame structure consist of the station.

If there are 100 stations, the total cost of them is 1171.5 million. Dominant economic benefits are mainly vending machine revenue and advertising revenue. Through public tender at the start, we get long-term cooperation projects and initial operating funds. The hidden economic benefits should also be taken into account. It includes the output of electricity, the savings of coal combustion and the cost of pollution disposal in power generation. The annual revenue of the station is shown in table 3 (we take 100 stations as an example).

Table 3 nnual revenue of the station

\begin{tabular}{|c|c|}
\hline Item & Annual income/ million \\
\hline Advertising and commodity income & 201.6 \\
\hline Energy economic benefits & 330.079 \\
\hline Total & 531.679 \\
\hline
\end{tabular}

Average annual generating capacity of a station is $23002 \mathrm{kWh}$. The average daily power generation is $63.02 \mathrm{kWh}$. We get an electric bicycle needs $0.48 \mathrm{kWh}$ from no power to full power. Besides electricity used by station equipment, 90 electric bicycles can be charged per day. We get $¥ 1$ from a person charged for his electric bicycle. The annual economic benefits is $¥ 32,900$. The income of 100 stations is 3.20 million. If in thermal power plant, about $10.5 \mathrm{t}$ standard coal annually can be saved. (Thermal power plant coal consumption is $320 \mathrm{~g} / \mathrm{kWh}$ in 2016). About $22.5 \mathrm{t}$ carbon dioxide, $4.6 \mathrm{t}$ sulfur dioxide and $0.87 \mathrm{t}$ soot can be reduced. That is, we can save 0.656 million of the corresponding treatment cost.

To sum up, the total cost of 100 post stations is 11.715 million. Annual advertising and commodity income is 2.016 million. The annual economic income is 330.079 million. The total income is 531.679 million. Remove the relevant operating and maintenance cost, these income can cover the cost in three years. These stations can not only save energy, and protect environment, but also be economic.

\section{Innovative Features}

The design of the public bicycle station upgrades the public bicycle with scientific and innovative methods. There are some innovative features compared with the past method,

Use Distributed Photovoltaic Power Generation Efficiently. Distributed photovoltaic power 
generation is a system that converts solar energy directly into electrical energy. It advocates the nearest power generation, the nearest conversion, the nearest use of the principle. This not only can effectively improve the same size photovoltaic power generation capacity, but also effectively reduce the power loss in the boost and long-distance transport.

Save Energy and Protect Environment. The solar panels used to generate electricity are versatile. On the one hand, it can supply electricity to public electric vehicles and the surrounding area. On the other hand, it also serves as a roof to meet the parking requirements of public bicycles, which slows down the damage rate of public bicycles.

People-oriented. The design of the station avoids cushion damp in rainy days and hot when the cushion temperature is too high. It also provides users with shelter in rainstorm day. There is a leisure area in the station, where users can buy food and drink at the vending machine. At the same time, the area is covered with the WIFI for users.

Economic. There are electronic screens in the station. They can not only set the advertising position for investment, but also be used for enterprises to publish job information. We charge appropriate money for these items, which maximize the benefits. The establishment of the electronic screen can reduce paper ads, which improve the aesthetic level.

According to local Conditions. Reasonably design the appearance of the station, pay attention to the aesthetic requirements of urban construction. Make public bicycle management and scheduling convenient, at the same time, make full use of geographical advantages to invest.

\section{Conclusion}

short, the station is of great market prospect. The design of humanized public bicycle station based on solar energy is friendly environmental and practical operated, which solves the charging problems for ordinary residents. With the development of photovoltaic technology and microelectronics technology, the development of electric bicycles will improve traffic structure. The construction of this kind of station will contribute to the use and management of pubic electric bicycles. It is really necessary to build the station.

\section{References}

[1] Wang Wei. Solar photovoltaic power generation parking shed energy-saving emission reduction program - Shanghai Maritime University as an example [J]. Market Weekly: theoretical research, 2015 (8): 39-41.

[2] Zhu Dandan, Yan Da. Study on the optimum inclination of solar panels [J]. Building Science, 2012 (s2): 277-281.

[3] Li Mingyang. Independent photovoltaic power generation system control strategy and its application [D]. Central South University. 2010.

[4] Klein S A. Calculation of monthly average insolation on tilted surfaces [J]. Solar Energy, 1977, 19(4):325-329.

[5] Zheng Zhiheng. Electric vehicle charging system construction exploration [J]. Industry and Technology Forum, 2011, 10 (23): 90-91.

[6] Buy army, Bai Rongli, Dai Xiaoliang, etc. New solar photovoltaic shed research and application [J]. Solar, 2013 (22): 52-54.

[7] Zhu Enlai. Green energy-saving photovoltaic carport [J]. China Hospital Building and Equipment, 2013 (11): 45-46.

[8] Wang Mingzhi, Han Guangyu, Li Ting, etc. Solar panel design [J]. Shandong Industrial Technology, 2015 (10): 58-58.

[9] Koutroulis E, Kalaitzakis K. Novel battery charging regulation system for photovoltaic applications [J]. IEE Proceedings - Electric Power Applications, 2006, 151(2):191-197.

[10] http://baike.so.com/doc/5385351-5621798.html. 